\title{
Size Induced Structural and Magnetic Properties of Nanostructured Cobalt Ferrites Synthesized by Co-precipitation Technique
}

\author{
Bekam Dengia Nagasa ${ }^{1}$, Raghavender A. ${ }^{1^{\star}}$, Kebede Legesse Kabeta ${ }^{1}$, Anjaneyulu $\mathrm{T}^{2}$, \\ Melkamu Biyane Regasa ${ }^{3}$
}

\author{
${ }^{1}$ Department of Physics, College of Natural and Computational Sciences, Wollega University, \\ Post Box No: 395, Nekemte, Ethiopia \\ ${ }^{2}$ Department of Physics, Narasaraopet Engineering College, Narasaraopet - 522 601, Andhra Pradesh, India \\ ${ }^{3}$ Department of Chemistry, College of Natural and Computational Sciences, Wollega University, \\ Post Box No: 395, Nekemte, Ethiopia
}

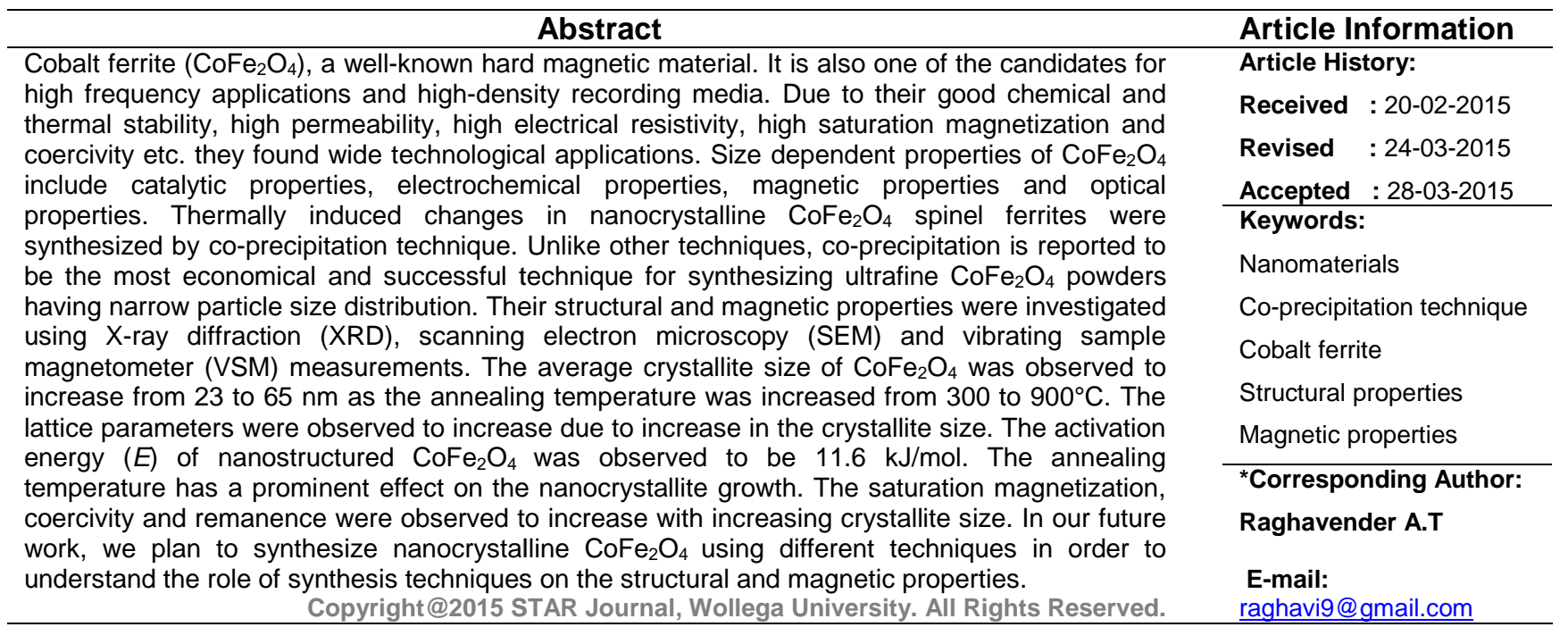

\section{INTRODUCTION}

Nanocrystalline spinel ferrites are of great interest because of their novel properties and also in understanding the fundamental properties point of view. In fact, there are number of studies which explains the magnetic properties at the atomic level. In addition, the structural properties and the rich crystallography of spinel ferrites offer excellent opportunities for understanding and fine tuning the magnetic properties (Chen et al., 1996). The cation distribution of spinel ferrites is influenced by the type of chemical environment, doping elements, synthesis techniques, crystallite size and the annealing process.

The magnetic properties of $\mathrm{CoFe}_{2} \mathrm{O}_{4}$ nanomaterials are determined by many factors like chemical composition, type of crystal lattice, shape, morphology and interactions of particles with surrounding matrix (Zhang et al., 2004). By changing the crystallite size, shape, composition, and structure, one can control the magnetic properties. However, these factors cannot always be controlled during synthesis of nano materials.
Therefore, the properties of nanomaterials even for the same type of ferrites are different. In the last few decades, $\mathrm{CoFe}_{2} \mathrm{O}_{4}$ materials have been widely investigated due to their high excellent chemical stability, high coercivity and saturation magnetization, mechanical hardness, and electromagnetic properties, which make this material a suitable candidate for the recording devices, magnetic cards and in electronic components (Alivisatos, 1996; Sugimoto, 1999 and Fan et al., 2009).

In this present work, we aimed to synthesize nanocrystalline cobalt ferrites using co-precipitation technique which is one of the most economical routes and consumes very less time over other synthesis techniques. The results of crystallite size dependent structural and magnetic properties of cobalt ferrites are presented in detail.

\section{MATERIALS AND METHODS}

Nanostructured $\mathrm{CoFe}_{2} \mathrm{O}_{4}$ were synthesized using coprecipitation technique (Raghavender et al., 2011; 


\section{Bekam Dengia Nagasa et alo,}

Berhanu et al., 2014). The AR grade sodium hydroxide $(\mathrm{NaOH})$, Cobalt (II) nitrate hydrate $\left(\mathrm{Co}\left(\mathrm{NO}_{3}\right)_{2} \cdot 6 \mathrm{H}_{2} \mathrm{O}\right)$, ferric (III) nitrate nonahydrate $\left(\mathrm{Fe}\left(\mathrm{NO}_{3}\right)_{3} \cdot 9 \mathrm{H}_{2} \mathrm{O}\right)(98 \%)$ were used as starting materials. The metal nitrates were dissolved together in minimum amount of deionized water to get a clear solution. $\mathrm{NaOH}$ solution was added drop by drop to metal nitrates solution under vigorous stirring. The precipitation occurred immediately to change the reaction solution to dark brown. The entire reaction was carried out at $75{ }^{\circ} \mathrm{C}$ for $2 \mathrm{~h}$. The $\mathrm{pH}$ of the solution was varied by $\mathrm{NaOH}$. The resulting precipitates were washed with deionized water and ethanol several times. The resulting precipitates was dried at $200{ }^{\circ} \mathrm{C}$ for $3 \mathrm{~h}$. The structural characterization of precipitates powders was carried out using Philips (France) X-ray diffraction (XRD) system with $\mathrm{Ni}$ filter using $\mathrm{Cu}-\mathrm{K} \alpha$ radiation (wave length $\lambda=1.54 \mathrm{~A}^{\circ}$ ). The morphology was verified using FEI Quanta (USA) FEG 200 High Resolution Scanning Electron Microscope (HR-SEM). Room temperature magnetic properties were investigated using Lakeshore (USA) vibrating sample magnetometer (VSM 7410).

\section{RESULTS AND DISCUSSIONS}

Figure 1 shows the X-ray diffraction patterns of $\mathrm{CoFe}_{2} \mathrm{O}_{4}$ samples annealed at temperatures from 300 to $900{ }^{\circ} \mathrm{C}$. The crystallite size was observed to increase from 23 to $65 \mathrm{~nm}$ due to increase in the annealing temperature as shown in Figure 2 and Table 1. The crystallite size was evaluated from the most intense (311) peak employing the Scherrer formula

$$
D=\frac{0.9 \lambda}{\beta \cos \theta}
$$

where $\beta$ is the angular line width at half maximum intensity and $\theta$ is the Bragg angle for the actual peak.

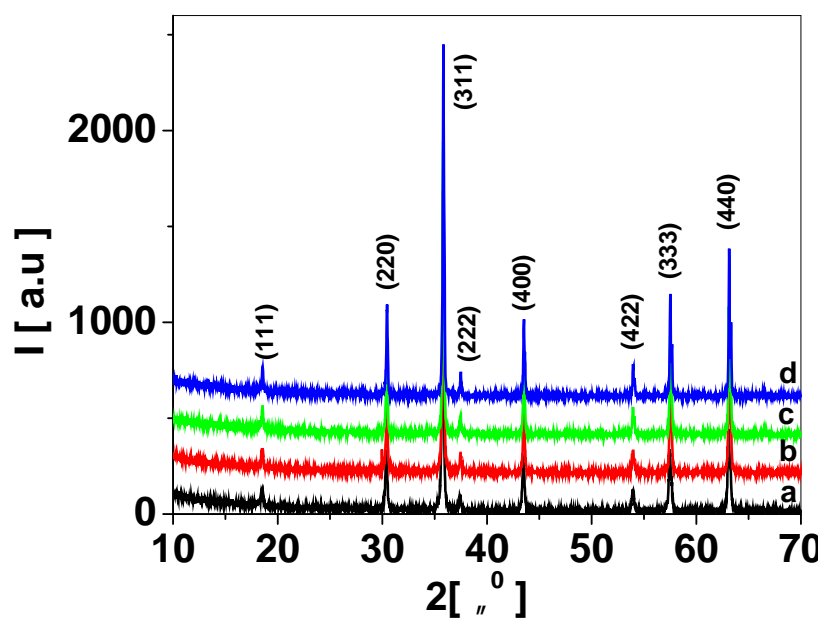

Figure 1: X-ray diffraction patterns of $\mathrm{CoFe}_{2} \mathrm{O}_{4}$ samples annealed at temperatures (a) $300^{\circ} \mathrm{C}$, (a) $500^{\circ} \mathrm{C}$, (a) $700{ }^{\circ} \mathrm{C}$ and (a) $900{ }^{\circ} \mathrm{C}$

Table.1: Dependence of crystallite size $(D)$, lattice constants $(a)$, saturation magnetization $\left(M_{s}\right)$, remanence magnetization $\left(M_{r}\right)$, coercivity $\left(H_{c}\right)$ and remanence ratio $\left(M_{r} / M_{s}\right)$

\begin{tabular}{ccccccc}
\hline $\begin{array}{c}\text { Temp. } \\
\left({ }^{\circ} \mathbf{C}\right)\end{array}$ & $\begin{array}{c}\mathbf{D} \\
(\mathbf{n m})\end{array}$ & $\begin{array}{c}\mathbf{a} \\
(\AA)\end{array}$ & $\begin{array}{c}\mathbf{M}_{\mathbf{s}} \\
(\mathbf{e m u} / \mathbf{g})\end{array}$ & $\begin{array}{c}\mathbf{M}_{\mathbf{r}} \\
(\mathbf{e m u} / \mathbf{g})\end{array}$ & $\begin{array}{c}\mathbf{H}_{\mathbf{c}} \\
(\mathbf{O e})\end{array}$ & $\begin{array}{c}\boldsymbol{M}_{\mathbf{r}} / \\
\boldsymbol{M}_{\boldsymbol{s}}\end{array}$ \\
\hline 300 & 23 & 8.299 & 9.13 & 5.09 & 915 & 0.56 \\
500 & 31 & 8.304 & 18.2 & 9.87 & 979 & 0.54 \\
700 & 54 & 8.308 & 23.3 & 10.42 & 1386 & 0.44 \\
900 & 65 & 8.314 & 27.4 & 13.86 & 1850 & 0.5 \\
\hline
\end{tabular}

Sci. Technol. Arts Res. J., Jan-March 2015, 4(1): 84-87

The increase in the crystallite size is due to increase in the volume of the grains. When the particles are in nanoregime, due to increase in the annealing temperature the grain growth takes place (Kumar et al., 2008). As observed from Figure 1, the XRD lines are broad and the broadening of the peaks decreases with increasing annealing temperature. Further, the increase in the intensity of X-ray diffraction shows improved crystallinity and gradual increase in the crystallite sizes of $\mathrm{CoFe}_{2} \mathrm{O}_{4}$ as a function of heat treatment process.

The lattice constants were calculated from the most intense (311) peak of the XRD and the corresponding values are presented in Table. 1. The lattice constants were observed to be nearly equal to that of bulk $\mathrm{CoFe}_{2} \mathrm{O}_{4}$. The lattice constants were observed to increase from $8.299 \AA$ to $8.314 \AA$ with increasing annealing temperature from 300 to $900{ }^{\circ} \mathrm{C}$ as shown in Figure 2 and Table 1. The observed change in the lattice constants with annealing temperature is the evidence of structural changes taking place in $\mathrm{CoFe}_{2} \mathrm{O}_{4}$ (Singh et al., 2004). This can be explained in terms of a meta-stable cation distribution in nanocrystallies. Since on increasing the annealing temperature the crystallite size $D$ increases, the lattice constants $a$ is expected to increase (Chen et al., 1996, Oliver et al., 2000).

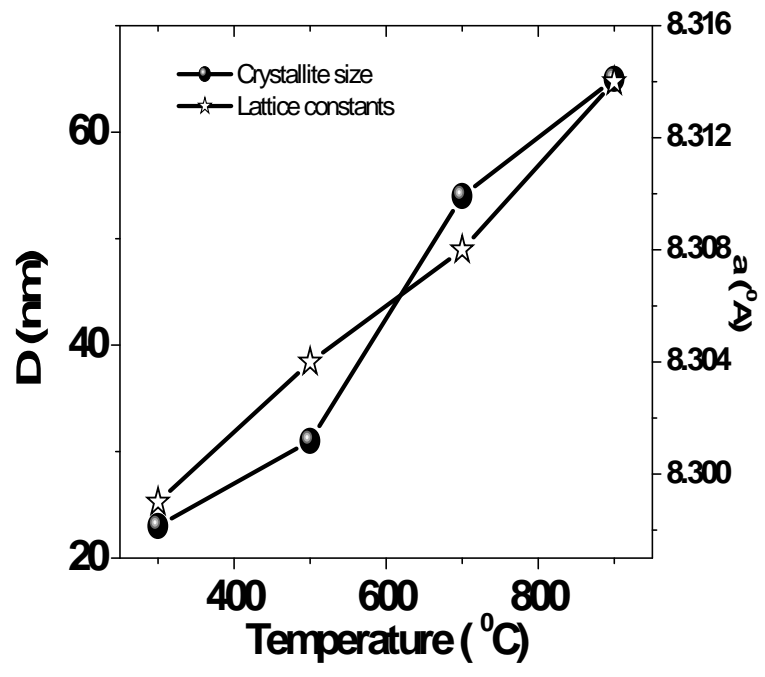

Figure 2: Dependence of crystallite size $(D)$ and lattice constants $(a)$ on the annealing temperatures of $\mathrm{CoFe}_{2} \mathrm{O}_{4}$ samples

The annealing temperature has prominent effect on the $\mathrm{CoFe}_{2} \mathrm{O}_{4}$ crystallite size. This is directly related to the crystallization of the nanocrystals. A straight line of In (d) against $1 / T$ (Figure 3 ) is plotted according to the Scott equation given below under the condition of homogeneous growth rate of nanocrystallite (Scott, 1983; Yang et al., 2004). The Scott equation approximately describes the growth rate of nanocrystallites from thermal treatment of amorphous compound:

$$
d=C \exp (-E / R T)
$$

where $d$ is the XRD crystallite size, $C$ is a constant, $E$ is the activation energy for grain growth, $R$ is the ideal gas constant and $T$ is the absolute temperature. 
Bekam Dengia Nagasa et al.,

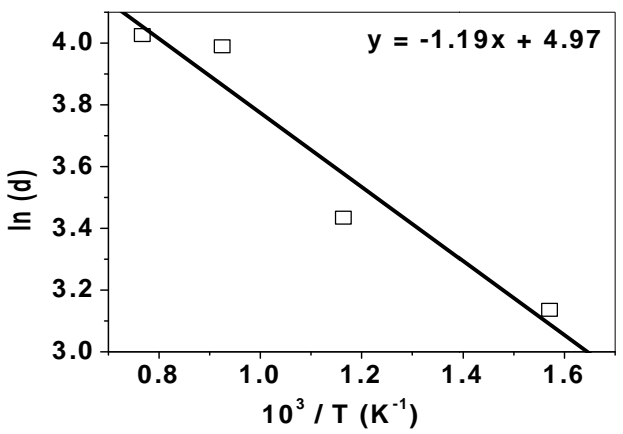

Figure 3: Plot of $\ln (d)$ against 1/T. Line presents a linear fit for $\ln (d)$ vs $1 / T$ dependence

There exists a good linear relationship between Ind and $1 / T$. $E$ values could be calculated from the slope of the straight line, presented in Figure 3 as $E=11.6 \mathrm{~kJ} / \mathrm{mol}$. It can be considered that the grain grows primarily by means of an interfacial reaction. It also shows that growth of Cobalt ferrite nanocrystals are easily effected by

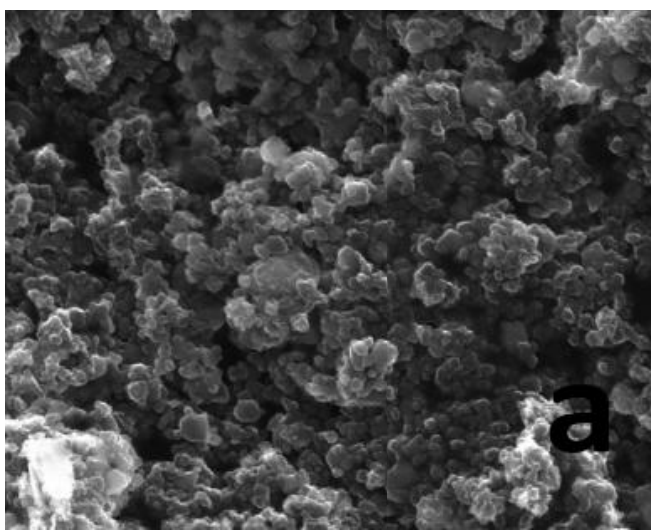

Figure 4: $\mathrm{SEM}$ images of $\mathrm{CoFe}_{2} \mathrm{O}_{4}$ samples anned

The room-temperature hysteresis loops for the samples annealed at temperatures from 300 to $900^{\circ} \mathrm{C}$ are shown in Figure 5. The derived parameters from the hysteresis loops are presented in Table. 1. The saturation magnetization $\left(M_{s}\right)$ for the sample annealed at $300^{\circ} \mathrm{C}$ is observed to be $9.13 \mathrm{emu} / \mathrm{g}$, which is very much smaller than the saturation magnetization of bulk $\mathrm{CoFe}_{2} \mathrm{O}_{4}$. As the annealing temperature increased to $900^{\circ} \mathrm{C}$, the magnetization attains the value of $27.4 \mathrm{emu} / \mathrm{g}$, which is comparable to the saturation magnetization value of $\mathrm{CoFe}_{2} \mathrm{O}_{4}$ synthesized from other techniques (Raghavender, 2013). The discrepancy in the observed magnetization in our case might be due to several facts such as, synthesis technique and conditions, chemical used, annealing temperature, grain / particle size, cluster size (Singh, 2013).

The saturation magnetization values for of $\mathrm{CoFe}_{2} \mathrm{O}_{4}$ samples was observed to increase with increase in crystallite size. This kind of behavior was observed for $\mathrm{CoFe}_{2} \mathrm{O}_{4}$ (Shafi et al., 1998; Gharagozlou, 2009; Haneda et al., 1988), $\mathrm{NiFe}_{2} \mathrm{O}_{4}$ (Zhang et al., 2004; Sepelak et al., 2007), and $\mathrm{MnFe}_{2} \mathrm{O}_{4}$ (Muroi et al., 2001) synthesized by other techniques. When the crystallite size increases, the redistribution of cations in the lattice takes place and is reported to influence the magnetic properties of ferrites (Wang, 2006 and Kodama et al., 1996). It is clearly observed that the saturation magnetization depends strongly on the crystallite size. The magnetization for ferromagnetic material usually increases with increasing
Sci. Technol. Arts Res. J., Jan-March 2015, 4(1): 84-87

annealing temperature, which is confirmed from Figure 3. Our activation value $E=11.6 \mathrm{~kJ} / \mathrm{mol}$ is much less than $18.5 \mathrm{~kJ} / \mathrm{mol}$ for $\mathrm{CoFe}_{2} \mathrm{O}_{4}$ prepared by ball milling (Yang et al., 2004).

Figure 4 presents the SEM images of $\mathrm{CoFe}_{2} \mathrm{O}_{4}$ samples annealed at 500 and $900{ }^{\circ} \mathrm{C}$. The SEM images suggest that, there is slight agglomeration among the particles. The nanocrystals distinctly exhibit narrow particle size distribution and present mainly sphericity. The SEM image of the sample annealed at $500{ }^{\circ} \mathrm{C}$ (See Figure 4(a)) show the microstructure with fairly smaller grain size. As the annealing temperature was increased to $900{ }^{\circ} \mathrm{C}$, a non-uniform grain growth with the presence of intragranular pores were observed (Figure 4(b)). Higher annealing temperature may lead to abnormal grain growth and closed pores. These kinds of pores were generally accounted for poor physico-mechanical properties and which may have significant affect on the structural and magnetic properties.

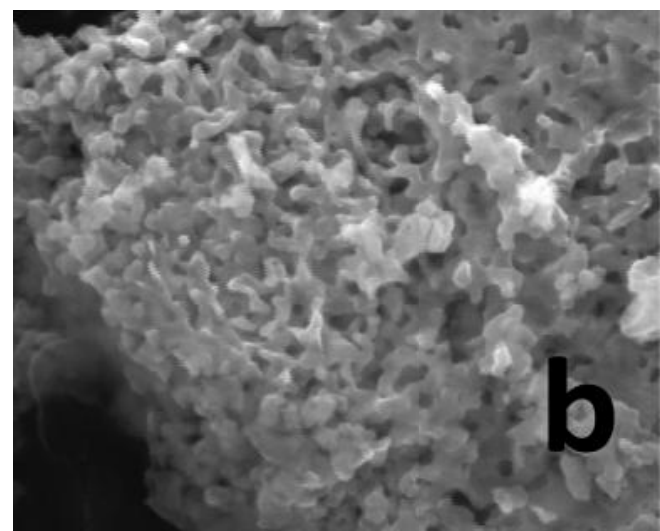

(a) $500{ }^{\circ} \mathrm{C}$ and (b) $900{ }^{\circ} \mathrm{C}$.

crystallite size (Ahmed et al., 2009). The same argument is valid for remanence magnetization also.

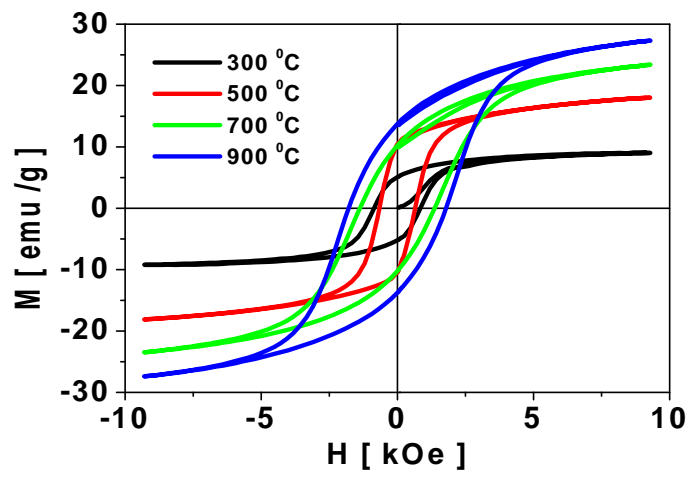

Figure 5: Room temperature magnetization measurements for $\mathrm{CoFe}_{2} \mathrm{O}_{4}$ samples annealed at different temperatures

Coercivity $\left(\mathrm{H}_{\mathrm{c}}\right)$ was observed to increase from 915 to 1850 Oe as the crystallite size increased from 23 to 65 $\mathrm{nm}$. The coercivity was observed to depend strongly on the crystallite size. The $M_{r} / M_{s}$ ratio (remanent magnetization to saturation magnetization) decreased with increase in the crystallite size. The $M_{r} / M_{s}$, values indicates the fraction of superparamagnetic particles in the synthesized samples and the decrease in these values may be due to the existence of spin canting (Jiang 


\section{Bekam Dengia Nagasa et al.,}

et al., 1999).. One of the possibilities of spin canting may be due to surface and interface effect (Ahmed et al., 2009). The remanent ratio $M_{r} / M_{s}$, is a characteristic parameter of the material and is dependent on the anisotropy (Singh et al., 2004), indicating the ease with which the magnetization direction is reoriented to the nearest easy axis magnetization direction after the magnetic field is removed. The lower the $M_{r} / M_{s}$ ratio, the more isotropic the material will be. The values of $M_{r} / M_{s}$ varied from 0.56 to 0.44 with increase in crystallite size except for the $65 \mathrm{~nm}$ particles. The observed variation in the coercivity field and remanence ratio with crystallite size can be explained on the basis of domain structure, critical size, and the anisotropy of the crystal (Qu et al., 2006; Vasic et al., 2006 and George et al., 2006). It is worth mentioning that the magnetic properties of nanocrystalline $\mathrm{CoFe}_{2} \mathrm{O}_{4}$ depends on the synthesis technique and conditions.

\section{CONCLUSIONS}

Nanocrystalline $\quad \mathrm{CoFe}_{2} \mathrm{O}_{4}$ were successfully synthesized using co-precipitation technique. The structural and magnetic properties were investigated using X-ray diffraction, scanning electron microscopy and magnetization measurements. The average crystallite size of $\mathrm{CoFe}_{2} \mathrm{O}_{4}$ was observed to increase from 23 to $65 \mathrm{~nm}$ as the annealing temperature was increased from 300 to $900^{\circ} \mathrm{C}$. The lattice parameters were observed to increase with increasing crystallite size due to changes in the structural properties. The magnetic properties exhibit a strong dependence on the crystallite size. Magnetization was observed to increase from 9.13 to $27.4 \mathrm{emu} / \mathrm{g}$. The coercivity was observed to increase from 915 to $1850 \mathrm{Oe}$.

\section{Conflict of Interest}

Authors declared no conflict of interest.

\section{REFERENCES}

Ahmed, Y.M.Z., Hessien, M.M., Rashad, M.M., Ibrahim, I.A. (2009). Nano-crystalline copper ferrites from secondary iron oxide (mill scale). Journal of Magnetism and Magnetic Materials 321: 181-187.

Alivisatos, A.P. (1996). Semiconductor clusters, nanocrystals, and quantum dots. Science 271:933-37.

Berhanu, H., Raghavender, A.T., Kebede, L., Anjaneyulu, T. (2014). Ferromagnetic Behavior in Zinc Ferrite Nano particles Synthesized using Coprecipitation Technique. Science Technology Arts Research Journal 3: 85-88.

Chen, J.P., Sorensen, C.M., Klabunde, K.J., Hadjipanayis, G. C., Devlin, E., Kostikas, A. (1996). Size-dependent magnetic properties of $\mathrm{MnFe}_{2} \mathrm{O}_{4}$ fine particles synthesized by coprecipitation. Physical Review B 54: 9288-9296.

Fan, H-M., Yi, J-B., Yang, Y., Kho, K-W., Tan, H-R., Shen, ZX., Ding, J, Sun, X-W., Malini, M.C., Feng, Y.P. (2009). Single-crystalline $\quad \mathrm{MFe}_{2} \mathrm{O}_{4}$ nanotubes/ nanorings synthesized by thermal transformation process for biological applications. ACS Nano 3: 2798-2808.

George, M., Mary John, A., Nair, S.S., Joy, P.A., Anantharaman M. R. (2006). Finite size effects on the structural and magnetic properties of sol-gel synthesized $\mathrm{NiFe} 2 \mathrm{O} 4$ powders. Journal of Magnetism and Magnetic Materials 302: 190-195.

Gharagozlou, M. (2009). Synthesis, characterization and influence of calcination temperature on magnetic properties of nanocrystalline spinel Co-ferrite prepared by
Sci. Technol. Arts Res. J., Jan-March 2015, 4(1): 84-87

polymeric precursor method. Journal of Alloys and Compounds 486: 660-665.

Haneda, K., Morrish, A. H. (1988). Noncollinear magnetic structure of $\mathrm{CoFe} 2 \mathrm{O} 4$ small particles Journal of Applied Physics 63: 4258-4260.

Jiang, J.Z., Goya, G.F., Rechenberg, H.R. (1999). Magnetic properties of nanostructured $\mathrm{CuFe}_{2} \mathrm{O}_{4}$. Journal of Physics: Condensed Matter 11: 4063-4078.

Kodama, R.H., Berkowitz, A.E., McNiff, Jr E.J., Foner, S. (1996). Surface Spin Disorder in $\mathrm{NiFe}_{2} \mathrm{O}_{4}$ Nanoparticles. Physical Review Letters 77: 394-397.

Kumar, V., Rana, A., Yadav, M.S., Pant, R.P. (2008). Sizeinduced effects on nanocrystalline $\mathrm{CoFe}_{2} \mathrm{O}_{4}$. Journal of Magnetism and Magnetic Materials 320: 1729-1734.

Muroi, M., Street, R., McCormick, P.G., Amighian, P. (2001). Magnetic properties of ultrafine $\mathrm{MnFe}_{2} \mathrm{O}_{4}$ powders prepared by mechanochemical processing Physical Review B 63: 184414-184417.

Oliver, S.A., Harriss, V.G., Hamdeh, H.H., Ho, J.C. (2000). Large zinc cation occupancy of octahedral sites in mechanically activated zinc ferrite powders. Applied Physics Letters 76: 2761-2763.

Qu, Y., Yang, H., Yang, N., Fan, Y., Zhu, H., Zou, G. (2006). The effect of reaction temperature on the particle size, structure and magnetic properties of coprecipitated $\mathrm{CoFe}_{2} \mathrm{O}_{4}$ nanoparticles. Materials Letters 60: 3548-3552.

Raghavender, A.T. (2013). Synthesis and Characterization of Cobalt Ferrite Nanoparticles. Science Technology and Arts Research Journal 2: 01-04.

Raghavender, A.T., Nguyen Hoa Hong. (2011). Dependence of Néel temperature on the particle size of $\mathrm{MnFe}_{2} \mathrm{O}_{4}$. Journal of Magnetism \& Magnetic Materials 323: 2145-47.

Scott, M.G. (1983). Amorphous Metallic Alloys, Butterworths, London, Pp. 151.

Sepelák, V., Bergmann, I., Feldhoff, A., Heitjans, P., Krumeich, F., Menzel, D., Litterst, F.J., Campbell, S.J., Becker, K.D. (2007). Nanocrystalline Nickel Ferrite, $\mathrm{NiFe}_{2} \mathrm{O}_{4}$ : Mechanosynthesis, Nonequilibrium Cation Distribution, Canted Spin Arrangement, and Magnetic Behaviour Journal of Physics and Chemistry C 111: 50265033.

Shafi, K.V.P.M., Gedanken, A., Prozorov, R. (1998). Sonochemical preparation and size-dependent properties of nanostructured $\mathrm{CoFe}_{2} \mathrm{O}_{4}$ particles Journal of Balogh Chemistry Materials 10: 3445-3450.

Singh, A.K., Goel, T.C., Mendiratta, R.G. (2004). Lowtemperature synthesis of $\mathrm{Mn}_{0.2} \mathrm{Ni}_{0.2} \mathrm{Zn}_{0.6} \mathrm{Fe}_{2} \mathrm{O}_{4}$ ferrites by citrate precursor method and study of their Properties. Physica Status Solidi (a) 201: 1453 - 1457.

Singh R. J. (2013). Unexpected magnetism in nanomaterials. Journal of Magnetism and Magnetic Materials 346: 58-73.

Sugimoto M., (1999). The past, present, and future of ferrites. Journal of the American Ceramic Society 82: 269-280.

Vasic, M., Antic, B., Kremenovic, A. (2006). Zn,Ni ferrite/NiO nanocomposite powder obtained from acetylacetonato complexes. Nanotechnology 17: 4877-4884.

Wang, J. (2006). Prepare highly crystalline $\mathrm{NiFe}_{2} \mathrm{O}_{4}$ nanoparticles with improved magnetic properties. Material Science Engineering B 127: 81-84.

Yang, H., Zhang, X., Huang, C., Yang, W., Qiu, G. (2004). Synthesis of $\mathrm{ZnFe}_{2} \mathrm{O}_{4}$ nanocrystallites by mechano chemical reaction. Journal of Physics and Chemistry of Solids 65: 1329-1332. 
Zhang, Y.D., Ge, S.H., Zhang, H., Hui, S., Budnick, J.I., Hines, W.A., Yacaman, M.J., Miki, M. (2004). Effect of spin disorder on magnetic properties of nanostructured Ni-ferrite. Journal of Applied Physics 95: 7130-7132. 